\title{
A Daily Glass of Red Wine and Lifestyle Changes Do Not Affect Arterial Blood Pressure and Heart Rate in Patients with Carotid Arteriosclerosis after 4 and 20 Weeks
}

\author{
Dirk W. Droste $^{a}$ Catalina Iliescu $^{b} \quad$ Michel Vaillant ${ }^{c} \quad$ Manon Gantenbein $^{b}$ \\ Nancy De Bremaeker ${ }^{\mathrm{b}} \quad$ Charlotte Lieunard $^{\mathrm{b}}$ Telma Velez $^{\mathrm{b}}$ \\ Michèle Meyer ${ }^{b}$ Tessy Guth ${ }^{c}$ Andrea Kuemmerle ${ }^{d}$ Anna Chiotib \\ ${ }^{a}$ Department of Neurology, Centre Hospitalier de Luxembourg, Luxembourg, ${ }^{b} \mathrm{Clinical}$ and \\ Epidemiological Investigation Centre, ${ }^{\mathrm{c}}$ Methodology and Statistical Competence Centre, \\ and ${ }^{\mathrm{d} C e n t r e}$ of Health Studies, Centre de Recherche Public-Santé, Strassen, Luxemburg
}

Key Words

Alcohol $\cdot$ Carotid arteries $\cdot$ Diet $\cdot$ Blood pressure $\cdot$ Nutrition

\section{Abstract}

Background: Regular consumption of small amounts of red wine improves blood lipids. However, there is concern whether this beneficial effect might be counterbalanced by an increase in blood pressure (BP) and heart rate (HR), which are risk factors for cerebro-cardiovascular disease. In particular, we studied whether regular consumption of red wine with and without lifestyle changes (LC; healthy diet and physical activity advice) results in an increase in BP and HR. Methods: A prospective, unblinded randomized trial was performed in 108 patients $(67 \%$ men) with carotid atherosclerosis documented by ultrasound, a mean BP of $122 / 79 \mathrm{~mm} \mathrm{Hg}$ and a mean HR of $71 \mathrm{bpm}$ at inclusion in the study. Sixty-eight percent were known and treated hypertensives. The mean 24-hour BP at baseline was $122 / 79 \mathrm{~mm} \mathrm{Hg}$. Half of the study participants, the control group, was seen by a nurse at baseline, after 4 and after 20 weeks, and was instructed not to change their eating and physical activity habits. In the other half, a dietician performed five sessions of 30 min each (at baseline, after 1 week and after 2, 3 and 4 weeks) giving advice on healthy eating based on a Mediterranean diet and physical exercise. The recommendations given were the following: 5 portions of fruit/vegetables per day, a diet low in absolute fat, a preference of vegetable oil (olive or rapeseed oil), whole-grain products, poultry, low-fat dairy products, 1 fat and 1 lean fish meal per week, reduced consumption of red meat, and avoidance of pork, ready-made meals, sugar and excessive salt intake. In addition, regular consumption of 1 bar of dark chocolate ( $25 \mathrm{~g},>70 \%$ of cacao), $1-2$ tomatoes, and 
Droste et al.: A Daily Glass of Red Wine and Lifestyle Changes Do Not Affect Arterial $\mathrm{BP}$ and HR in Patients with Carotid Arteriosclerosis after 4 and 20 Weeks

3-5 walnuts as well as at least 30 min of moderate daily physical activity were recommended. Within these two groups, half of the patients were randomized either to avoid alcohol completely or to drink $100 \mathrm{ml}$ (women) or $200 \mathrm{ml}$ of red wine (men) daily. Results: Neither LC nor red wine had an effect on the mean systolic and diastolic 24-hour BP and HR after 4 and 20 weeks, as analyzed by general linear modeling. No difference was found for diurnal and nocturnal values. Conclusions: The possible beneficial effect of regular consumption of small amounts of red wine is not counterbalanced in the long term by an increase in the mean BP or HR in mainly normotensive and well-treated hypertensive patients with carotid atherosclerosis, neither in the patients given healthy lifestyle advice nor in those with a standard lifestyle. Yet, we remain cautious about actively advice patients to drink alcohol regularly given the well-known risks.

(c) 2013 S. Karger AG, Basel

\section{Introduction}

Lifestyle changes (LC) including physical exercise and a Mediterranean diet improve the lipid profile. Physical exercise mainly increases HDL and reduces triglycerides; LDL is hardly affected [1, 2]. In their recent meta-analysis, Kastorini et al. [3] found an increase in HDL and a decrease in triglycerides when comparing a Mediterranean diet with a conventional diet. Some of the studies included red wine and others did not. Three food items in particular have been shown to improve the lipid profile: dark chocolate, tomatoes and walnuts, the latter two being frequently part of a Mediterranean diet [4-9]. Mediterranean diets [3,10-12] as well as physical activity are known to lower blood pressure (BP) [10,12-14]. Alcohol consumption and especially binge drinking are risk factors for high BP and cerebro-cardiovascular disease $[15,16]$. Light to moderate alcohol consumption, and possibly in particular red wine consumption, is associated with a smaller risk for cerebro- and cardiovascular disease and an improved lipid profile [16-21]. Little is known on the effect of regular consumption of small quantities of alcohol on BP and heart rate (HR).

In this prospective, unblinded, randomized controlled trial, we assessed the effect of a small amount of red wine and LC, including the consumption of dark chocolate, tomatoes and walnuts associated with physical activity, on BP and HR in patients with arteriosclerosis documented by carotid ultrasound. In particular, we studied whether consumption of red wine on top of LC results in an increase in BP, thus counterbalancing the beneficial effect on blood lipids. The present work is part of the ALVINA project (an acronym of 'alimentation, vin, et activité physique' meaning 'nutrition, wine, and physical activity' in French), in which also other parameters were studied. The study outline, patients' baseline characteristics, results on lipids and the efficacy of lifestyle counseling are reported or submitted for publication elsewhere [22].

\section{Methods}

The study complies with the Declaration of Helsinki and was performed in Luxemburg after protocol approval by the National Research Ethics Committee (200801/06) and notification to the National Commission for Data Protection. The trial was registered at http:// www.clinicaltrials.gov (NCT01146132). The first patient was included on June 4, 2009, and the last follow-up visit took place on October 10, 2011.

Hundred and twenty-two patients were followed up to 20 weeks. The enrolled participants were outpatients of the Department of Neurology and had undergone carotid and intra- 
cranial bitemporal color-coded duplex sonography carried out with the Antares system (Siemens Healthcare, Erlangen, Germany). Inclusion criteria were age $>30$ years and the presence of plaques or stenosis without hemodynamic compromise (i.e. $<70 \%)$ in at least one common carotid artery, the carotid bifurcation or the internal carotid artery. Exclusion criteria were a history of ocular or cerebral ischemia within the last 3 months, atrial fibrillation, a repeatedly measured systolic BP (SBP) $>160 \mathrm{~mm}$ Hg or the incapacity to give informed consent. The experimental design of the study was a $2 \times 2$ factorial design. The patients were allocated to groups of different lifestyles in result of a randomization stratified for gender. Lots were drawn to generate the random allocation sequence, and block size was 4 . The intervention allocation was concealed in a nontransparent envelope. The random allocation sequence was generated by an independent staff member; patients were enrolled by the principal investigator and were assigned to interventions by the study nurse. A first group received no lifestyle counseling and the second one received lifestyle counseling at baseline and after $1,2,3$ and 4 weeks. Within each lifestyle group, the patients were either randomly advised to drink a glass of red wine a day ( 0.2 liter for males and 0.1 liter for females) or they were advised to avoid alcohol completely for the time of the study.

In the LC group, a dietician performed five sessions of 30 min each (at baseline, after 1 week and after 2, 3 and 4 weeks) giving advice on healthy eating based on a Mediterranean diet and physical exercise. In particular, 5 portions of fruit/vegetables per day, a diet low in absolute fat, a preference of vegetable oil (olive or rapeseed oil), whole-grain products, poultry, low-fat dairy products, 1 fat and 1 lean fish meal per week, reduced consumption of red meat and avoidance of pork, ready-made meals, sugar and excessive salt intake were recommended [23, 24]. A water intake of 1.5-2 liters a day was recommended as well. In addition, regular consumption of 1 bar of dark chocolate ( $25 \mathrm{~g}$, >70\% of cacao), 1-2 tomatoes, 3-5 walnuts as well as at least $30 \mathrm{~min}$ of moderate daily physical activity was recommended $[6,9,25,26]$. The control group (no LC) was seen at baseline, after 4 and after 20 weeks by a nurse who instructed the patients not to change their eating and physical activity habits. The patients allocated to the wine group (within the LC and the no LC groups) underwent three short sessions of counseling by the nurse concerning the intake of red wine of their choice (200 $\mathrm{ml}$ for males and $100 \mathrm{ml}$ for females) $[20,27,28]$.

For the 24-hour BP and HR monitoring, we used the Cardioline Walk200b system (CARDIOLINE S.p.A., Cavareno, Italy). Measurements were carried out every 20 min during daytime (7:00 a.m.-09:59 p.m.) and every 30 min during nighttime using the same upper arm in each individual for follow-up measurements.

The predefined primary endpoint of the study was a change in the mean 24-hour SBP assessed at baseline and at 20 weeks. Secondary endpoints were changes in the mean 24-hour DBP, the mean 24-hour HR, the mean diurnal and nocturnal SBP, the mean diurnal and nocturnal DBP and the mean diurnal and nocturnal HR assessed at baseline and at 20 weeks as well as at baseline and at 4 weeks. As there are gender differences in alcohol distribution and metabolism, general linear model analyses were also stratified by gender.

The intent-to-treat (ITT) and per-protocol (PP) populations were defined in order to show the effect of the intervention given the environment of the patients for the former, and to show the true effect of the intervention of all other parameters being controlled. The ITT population included only patients who had attended the first and at least the 4 -week visit. The PP included the ITT patients and excluded those who admitted not to have followed the instructions or who did not present themselves at the 20 -week visit. The ITT population was the primary population. The groups (defined by LC and red wine intake) were compared at their baseline values. For continuous variables, normality was verified using the ShapiroWilk test. Where the values were normally distributed, a two-sample t test was used. Otherwise, the Wilcoxon-Mann-Whitney test was applied. Dichotomous data was compared 
using Pearson's $\chi^{2}$ test. In case the expected cell frequencies were lower than 5 , Fisher's exact test was applied. A general linear model with Tukey-Kramer adjustment for multiple comparisons was used to assess the primary endpoints. The absolute change value represented the dependent value. In case the normality assumption of the model residuals was violated, ANOVA on ranks was used. A p value below 0.05 was considered significant. All tests were two-tailed, and all analyses were performed by using the SAS System v9.2 (SAS Institute, Cary, N.C., USA).

\section{Results}

The ITT population included 108 subjects. Out of the 122 selected patients, 14 were closed out because they dropped out of the study before the 4- or 20-week visit. The PP population excluded 3 patients of the wine group who never drank wine during the study, 3 patients who drank considerable amounts of alcohol in the abstinent group, and 2 patients who did not attend the 20 -week visit but had attended the 4 -week visit. Therefore, the PP population included 100 patients.

The groups were well balanced (table 1). The mean daily alcohol intake at baseline was $14.6 \mathrm{~g}$ with a maximum of $57 \mathrm{~g}$. No difference was found between the groups. There was homogeneity between the groups in all baseline parameters. No serious adverse events related to the study were recorded. Table 2 gives the distribution of the baseline BP values in relation to the classification of the European Society of Hypertension [29, 30]. Most subjects were normotensives (or treated hypertensives).

Table 3 gives the results for the primary endpoint and the secondary endpoints in the ITT population. There was no effect of the interventions on the 24-hour, diurnal and nocturnal SBP, DBP and the mean HR difference between the baseline and 4- and 20-week values, as analyzed by general linear modeling. In the PP analysis, however, despite the fact that the global explanation was not significant with $p=0.2142$, there was a significant effect of wine on the nocturnal HR ( $p=0.0178$, rank model) after 4 weeks. This effect was only significant in the LC group, indicating a higher nocturnal HR in the wine drinkers compared to the no wine drinkers with a mean difference of $4.2 \mathrm{bpm}$.

\section{Discussion}

Our study failed to find evidence of an effect of regular, small amounts of red wine on the mean 24-hour BP and HR in patients with carotid arteriosclerosis, neither after 4 weeks nor after 20 weeks. Therefore, the beneficial effect a daily glass of red wine on blood lipids is not counterbalanced by a raise in BP or HR [16-21]. We did not find any effect of LC including Mediterranean diet and physical exercise on BP and HR. Only the PP analysis in the LC group showed a higher nocturnal HR (mean difference $4.2 \mathrm{bpm}$ ) in the wine drinkers compared to the no wine drinkers.

Mediterranean diets are known to lower BP [3,10-12]. The effect is pronounced if weight loss is associated with the diet [31]; however, without weight loss, the situation is less clear and 2 large studies reported that there is only a beneficial effect on blood lipids but not on BP $[11,32]$. This is in line with our study, where no effects on weight and BP were found. Moreover, the DASH trial had already found that the effect of diet on BP is more pronounced in hypertensive patients [33]. The participants in our study were mainly normotensive (either primarily or treated). 


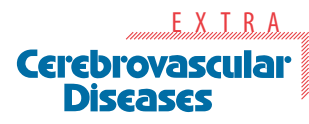

\begin{tabular}{l|l}
\hline \multicolumn{2}{l|}{ Cerebrovasc Dis Extra 2013;3:121-129 } \\
\hline DOI: $10.1159 / 000354847$ & $\begin{array}{l}\text { C 2013 S. Karger AG, Basel } \\
\text { www.karger.com/cee }\end{array}$ \\
\hline Droste et al.: A Daily Glass of Red Wine and Lifestyle Changes Do Not Affect Arterial
\end{tabular}

BP and HR in Patients with Carotid Arteriosclerosis after 4 and 20 Weeks

Table 1. Baseline demographic values, past medical history, BP treatment and mean BP and HR

\begin{tabular}{|c|c|c|c|c|c|c|c|}
\hline & No LC & LC & $\mathrm{p}$ value & Red wine & No red wine & $\mathrm{p}$ value & Total \\
\hline Number & 55 & 53 & & 56 & 52 & & 108 \\
\hline Mean age, years & $63.4(10.6)$ & $63.7(8.1)$ & n.s. & $64.1(9.1)$ & $63.0(9.9)$ & n.s. & $63.6(9.5)$ \\
\hline Men, \% & 69 & 64 & n.s. & 68 & 65 & n.s. & 67 \\
\hline Daily alcohol intake, g & $14.7(14.7)$ & $14.5(14.2)$ & n.s.* & $15.4(14.3)$ & $13.7(14.6)$ & n.s.* & $14.6(14.4)$ \\
\hline Daily alcohol intake of men, g & $16.2(14.5)$ & $15.2(11.9)$ & n.s. ${ }^{*}$ & $16.5(13.4)$ & $14.8(13.2)$ & n.s. ${ }^{*}$ & $15.7(13.3)$ \\
\hline Daily alcohol intake of women, $g$ & $11.4(14.9)$ & $13.4(18.0)$ & n.s.* & $13.0(16.0)$ & $11.8(17.2)$ & n.s.* & $12.4(16.4)$ \\
\hline Mean weight, kg & $81.6(16.2)$ & $77.2(16.3)$ & n. s. & $79.5(14.3)$ & $79.4(18.4)$ & n.s. & $79.4(16.3)$ \\
\hline Mean BMI & $27.8(4.2)$ & $27.3(4.5)$ & n.s. & $27.4(3.9)$ & $27.7(4.8)$ & n.s.* & $27.6(4.4)$ \\
\hline Smokers, \% & 11 & 4 & n.s. & 5 & 10 & n.s. & 7 \\
\hline Hypertension, \% & 69 & 66 & n.s. & 71 & 63 & n.s. & 68 \\
\hline Hyper-/dyslipidemia, \% & 76 & 72 & n.s. & 71 & 77 & n.s. & 74 \\
\hline Diabetes mellitus, \% & 13 & 11 & n.s. & 14 & 10 & n.s. & 12 \\
\hline Previous stroke, \% & 20 & 21 & n.s. & 25 & 15 & n.s. & 20 \\
\hline Previous TIA, \% & 15 & 9 & n.s. & 11 & 13 & n.s. & 12 \\
\hline Previous MI, \% & 11 & 8 & n.s. & 7 & 12 & n.s. & 9 \\
\hline Angina pectoris, $\%$ & 7 & 4 & n.s. & 5 & 6 & n.s. & 6 \\
\hline Intermittent claudication, $\%$ & 0 & 2 & n.s. & 0 & 2 & n.s. & 1 \\
\hline On ACE inhibitor, $\%$ & 4 & 11 & not tested & 4 & 12 & not tested & 7 \\
\hline On angiotensin II antagonist, \% & 56 & 32 & not tested & 55 & 33 & not tested & 44 \\
\hline On calcium antagonist, \% & 29 & 25 & not tested & 27 & 27 & not tested & 27 \\
\hline On beta blocker, \% & 29 & 38 & not tested & 41 & 25 & not tested & 33 \\
\hline On diuretic, $\%$ & 22 & 23 & not tested & 27 & 17 & not tested & 22 \\
\hline On renin inhibitor, $\%$ & 2 & 2 & not tested & 2 & 2 & not tested & 2 \\
\hline On alpha blocker, $\%$ & 5 & 6 & not tested & 5 & 6 & not tested & 6 \\
\hline Mean 24-hour systolic BP, mm Hg & $121.6(10.9)$ & $122.8(11.6)$ & n.s.* & $122.7(12.4)$ & $121.6(9.8)$ & n.s.* & $122.2(11.2)$ \\
\hline Mean 24-hour diastolic BP, mm Hg & $79.4(8.1)$ & $78.0(7.9)$ & n.s.* & $79.3(8.6)$ & $78.1(7.3)$ & n.s. ${ }^{*}$ & $78.7(8.0)$ \\
\hline Mean 24-hour HR, bpm & $71.4(7.3)$ & $70.5(7.7)$ & n.s.* & 70.8 (7.1.) & $71.1(8.0)$ & n.s. & $70.9(7.5)$ \\
\hline Mean diurnal SBP, mm Hg & $124.2(10.5)$ & $126.1(12.0)$ & n.s.* & $126.1(12.5)$ & $124.1(9.7)$ & n.s.* & $125.1(11.2)$ \\
\hline Mean diurnal DBP, mm Hg & $83.4(8.9)$ & $82.3(8.6)$ & n.s. & $83.8(9.4)$ & $81.8(7.8)$ & n.s. & 82.9 (8.7) \\
\hline Mean diurnal HR, bpm & $74.8(7.8)$ & $73.5(8.2)$ & n.s. & $73.9(7.5)$ & $74.5(8.5)$ & n.s. & $74.2(8.0)$ \\
\hline Mean nocturnal SBP, mm Hg & $115.9(14.3)$ & $114.9(14.2)$ & n.s.* & $115.1(15.6)$ & $115.7(12.6)$ & n.s.* & $115.4(14.2)$ \\
\hline Mean nocturnal DBP, mm Hg & $70.4(8.6)$ & $68.2(9.0)$ & n.s. ${ }^{*}$ & $69.4(9.3)$ & $69.2(8.4)$ & n.s. ${ }^{*}$ & $69.3(8.8)$ \\
\hline Mean nocturnal HR, bpm & $63.7(8.2)$ & $63.2(7.7)$ & n.s. ${ }^{*}$ & $63.6(8.0)$ & $63.3(8.0)$ & n.s.* & $63.5(7.9)$ \\
\hline
\end{tabular}

Values in parentheses are SD. No differences were found between the LC and the no LC group and between the red wine and the no red wine group in the Student $t$ tests and Wilcoxon-Mann-Whitney tests (indicated by *), respectively. Categorical values were tested with the $\chi^{2}$ test or Fisher's exact test, respectively. TIA = Transient ischemic attack; MI = myocardial infarction; ACE = angiotensin-converting enzyme.

Table 2. Distribution of BP values at baseline for the whole cohort of 108 patients

\begin{tabular}{lllcccc}
\hline & Low & Normal & Borderline & Mild & Moderate & Severe \\
\hline Diurnal SBP & $0(0)$ & $91(84.26)$ & $8(7.41)$ & $7(6.48)$ & $2(1.85)$ & $0(0)$ \\
Diurnal DBP & $0(0)$ & $72(66.67)$ & $16(14.81)$ & $16(14.81)$ & $4(3.70)$ & $0(0)$ \\
Nocturnal SBP & $1(0.93)$ & $74(68.52)$ & $12(11.11)$ & $11(10.19)$ & $8(7.41)$ & $2(1.85)$ \\
Nocturnal DBP & $1(0.93)$ & $64(59.26)$ & $17(15.74)$ & $21(19.44)$ & $4(3.70)$ & $1(0.93)$ \\
\hline
\end{tabular}

Values are numbers of subjects with percentages in parentheses. The vast majority of the subjects was normotensive. To classify BP, we used the limits of the European Society of Hypertension. For orientation, normal diurnal SBP was 100-135 mm Hg, nocturnal SBP 91-120 mm Hg, diurnal DBP 65-85 mm Hg and nocturnal DBP 51-70 mm Hg [31, 33]. 


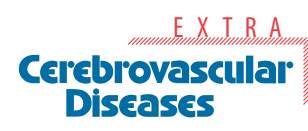

\begin{tabular}{l|l}
\hline \multicolumn{2}{l}{ Cerebrovasc Dis Extra 2013;3:121-129 } \\
\hline DOI: $10.1159 / 000354847$ & $\begin{array}{l}\text { C } 2013 \text { S. Karger AG, Basel } \\
\text { www.karger.com/cee }\end{array}$ \\
\hline Droste et al.: A Daily Glass of Red Wine and Lifestyle Changes Do Not Affect Arterial
\end{tabular}

Droste et al.: A Daily Glass of Red Wine and Lifestyle Changes Do Not Affect Arterial
BP and HR in Patients with Carotid Arteriosclerosis after 4 and 20 Weeks

Table 3. Absolute change of BP and HR

\begin{tabular}{|c|c|c|c|c|c|c|}
\hline & $\begin{array}{l}\text { No LC } \\
(n=55)\end{array}$ & $\begin{array}{l}\mathrm{LC} \\
(\mathrm{n}=53)\end{array}$ & $\mathrm{p}$ & $\begin{array}{l}\text { Red wine } \\
(n=56)\end{array}$ & $\begin{array}{l}\text { No red wine } \\
(n=52)\end{array}$ & $\mathrm{p}$ \\
\hline \multicolumn{7}{|l|}{ Baseline - 4 weeks } \\
\hline Mean 24-hour SBP, mm Hg & $-0.9(9.3)$ & $-1.3(8.6)$ & n.s. & $-1.6(9.6)$ & $-0.5(8.0)$ & n.s. \\
\hline Mean 24-hour DBP, mm Hg & $-0.0(5.9)$ & $-0.8(5.6)$ & n.s. & $-0.9(6.0)$ & $0.2(5.4)$ & n.s. \\
\hline Mean 24-hour HR, bpm & $-0.6(4.7)$ & $-0.4(6.1)$ & n.s. & $0.1(5.5)$ & $-1.1(5.3)$ & n.s. \\
\hline Mean diurnal SBP, mm Hg & $-0.5(9.3)$ & $-1.9(9.3)$ & n.s. & $-1.7(10.0)$ & $-0.6(8.5)$ & n.s. \\
\hline Mean diurnal DBP, mm Hg & $0.3(6.2)$ & $-1.1(6.5)$ & n.s. & $-1.0(6.4)$ & $0.3(6.3)$ & n.s. \\
\hline Mean diurnal HR, bpm & $-0.9(5.3)$ & $-0.1(6.4)$ & n.s.* & $0.1(5.9)$ & $-1.1(5.9)$ & n.s.* \\
\hline Mean nocturnal SBP, mm Hg & $-2.1(11.0)$ & $0.6(11.6)$ & n.s. & $-1.4(11.7)$ & $-0.2(11.0)$ & n.s. \\
\hline Mean nocturnal DBP, mm Hg & $-1.2(7.5)$ & $0.1(7.8)$ & n.s. & $-1.3(7.8)$ & $0.2(7.4)$ & n.s. \\
\hline Mean nocturnal HR, bpm & $-0.4(5.2)$ & $-1.1(6.7)$ & n.s. & $0.0(6.4)$ & $-1.5(5.3)$ & n.s. \\
\hline \multicolumn{7}{|l|}{ Baseline - 20 weeks } \\
\hline Mean 24-hour SBP, mm Hg & $-0.3(9.4)$ & $-0.5(10.5)$ & n.s.* & $-0.5(10.1)$ & $-0.3(9.7)$ & n.s.* \\
\hline Mean 24-hour DBP, mm Hg & $-0.1(6.3)$ & $-0.3(6.8)$ & n.s. & $-0.7(6.5)$ & $0.3(6.6)$ & n.s. \\
\hline Mean 24-hour HR, bpm & $1.2(5.6)$ & $0.2(5.0)$ & n.s.* & $0.9(5.6)$ & $0.4(5.0)$ & n.s.* \\
\hline Mean diurnal SBP, mm Hg & $-0.8(9.3)$ & $-1.4(11.4)$ & n.s.* & $-1.6(10.6)$ & $-0.5(10.2)$ & n.s.* \\
\hline Mean diurnal DBP, mm Hg & $-0.3(6.8)$ & $-0.5(8.4)$ & n.s. & $-1.4(7.6)$ & $0.7(7.5)$ & n.s. \\
\hline Mean diurnal HR, bpm & $0.9(5.1)$ & $0.1(5.7)$ & n.s. & $0.4(5.3)$ & $0.7(5.5)$ & n.s. \\
\hline Mean nocturnal SBP, mm Hg & $0.3(12.4)$ & $1.5(11.7)$ & n.s.* & $1.7(11.9)$ & $-0.0(12.2)$ & n.s.* \\
\hline Mean nocturnal DBP, mm Hg & $-0.0(7.7)$ & $-0.1(7.4)$ & n.s.* & $0.4(7.2)$ & $-0.6(7.9)$ & n.s.* \\
\hline Mean nocturnal HR, bpm & $0.3(6.4)$ & $0.4(6.2)$ & n.s. & $0.8(6.1)$ & $-0.2(6.5)$ & n.s. \\
\hline
\end{tabular}

Values in parentheses are SD. p values are from a general linear model. When the values were not normally distributed, ANOVA on ranks was used (indicated by *).

Physical activity has also been described to lower BP [10,12-14]. However, this effect seems to be restricted to younger patients. After 6 months, there was no effect of exercise on SBP and only a mild effect on DBP $(-2.2 \mathrm{~mm} \mathrm{Hg})$ in 55- to 75-year-old patients with mild hypertension compared to a control group [34]. A reason could be aortic stiffness in this age group, similar to the age group in our study.

Alcohol has a biphasic effect on BP and HR. An initial vasodilatation with a drop in BP is followed by vasoconstriction and a rise in BP [35-37]. The drop in BP is accompanied by a rise in HR and vice versa [35]. On the first day of alcohol intake, the mean 24-hour BP dropped and HR increased compared to baseline. However, after 7 days of regular alcohol intake at dinner, no changes in the mean 24-hour BP and HR were noted in 14 male habitual drinkers with essential hypertension in the study by Abe et al. [35]. However, after 7 days, BP was lower and HR higher between 6 p.m. and midnight. Between midnight and 8 a.m., BP was higher as compared to baseline [35]. We did not find any effect of regular alcohol intake on the 24-hour BP and HR values. Reasons for this finding were that (a) the time of alcohol intake was at the subject's discretion; (b) BP and HR were measured after 4 and 20 weeks, respectively, and (c) there was an attenuation of the BP and HR reaction to alcohol with time, which has already been described in the study by Abe [35].

Heavy alcohol consumption and binge drinking are risk factors for high BP and cerebrocardiovascular disease $[15,16]$. Cessation of heavy alcohol intake (100-380 g daily) in men reduced SBP and DBP by $7 \mathrm{~mm} \mathrm{Hg}$ and HR by 8 bpm after 1 month [38]. In our study, the mean daily alcohol intake at baseline was $14.6 \mathrm{~g}$ with a maximum of $57 \mathrm{~g}$ daily, and the amount studied was about 12 and $24 \mathrm{~g}$, respectively. These values were far lower and the effects of withdrawal and exposition were less pronounced, which explains our different results. During 
our study, a continuous, small amount of daily alcohol intake was administered, and binge drinking was discouraged in both the wine drinkers and the no wine drinkers.

Zilkens et al. [39] compared 4 weeks of control abstinence with similar periods of daily consumption of red wine $(375 \mathrm{ml})$, dealcoholized red wine $(375 \mathrm{ml})$ or beer $(1,125 \mathrm{ml})$ in 28 normotensive men in random order. The ambulatory SBP, DBP and HR were not different between control abstinence and dealcoholized red wine. However, compared with control abstinence, both red wine and beer increased awake SBP (2.9 and $1.9 \mathrm{~mm} \mathrm{Hg}$, respectively; $\mathrm{p}<0.05)$ and asleep HR (5.0 and $4.4 \mathrm{bpm} ; \mathrm{p}<0.05)$. The amount of alcohol used in this study ( $375 \mathrm{ml}$ of wine and 1,125 ml of beer, respectively) was higher than the one we used (100 and $200 \mathrm{ml}$ of red wine, respectively). This may explain why HR and BP did not change in the long term in our study. In the PP population of our study, there was only a transient increase in the nocturnal HR of the LC group that was drinking wine for 4 weeks as compared with the LC group that did not drink wine at all.

Alcohol shows interactions with BP medication. Drinkers show lower levels of telmisartan as compared to non-drinkers when taking the same dose of telmisartan [40]. A majority of the subjects in our study was on angiotensin II receptor antagonists. Nevertheless, there was no increase in BP in the wine-drinking group.

Our study demonstrates that in mainly normotensive and well-treated hypertensive patients with cerebrovascular disease, the possible effect of the regular intake of small amounts of red wine is not counterbalanced by an increase in the mean SBP or DBP or by an increase in HR in the long term. Limitations of our study are the relatively small number of participants subdivided into four groups and the fact that we studied the effect of counseling and not the actual change in behavior.

\section{Acknowledgments}

We are very grateful to Mrs. S. Spinelli (dietician) and to Prof. S. Senn (statistics) for their helpful comments.

The Centre de Recherche Public-Santé sponsored this study (rooms, personnel, technical devices and investigations). The Centre Hospitalier de Luxembourg authorized Prof. Droste to spend part of his working time on this study and provided rooms, logistical and secretarial support.

\section{Disclosure Statement}

None of the authors had a personal or financial conflict of interest.

\section{References}

1 Trejo-Gutierrez JF, Fletcher G: Impact of exercise on blood lipids and lipoproteins. J Clin Lipidol 2007;1:175181.

2 Brown WV, Fletcher GF, Wilson PW: Using exercise to reduce risk. J Clin Lipidol 2009;3:360-367.

-3 Kastorini CM, Milionis HJ, Esposito K, Giugliano D, Goudevenos JA, Panagiotakos DB: The effect of Mediterranean diet on metabolic syndrome and its components: a meta-analysis of 50 studies and 534,906 individuals. J Am Coll Cardiol 2011;57:1299-1313.

4 Buitrago-Lopez A, Sanderson J, Johnson L, Warnakula S, Wood A, Di AE, Franco OH: Chocolate consumption and cardiometabolic disorders: systematic review and meta-analysis. BMJ 2011;343:d4488.

$>5$ Tokede OA, Gaziano JM, Djousse L: Effects of cocoa products/dark chocolate on serum lipids: a meta-analysis. Eur J Clin Nutr 2011;65:879-886. 
Droste et al:: A Daily Glass of Red Wine and Lifestyle Changes Do Not Affect Arterial $\mathrm{BP}$ and HR in Patients with Carotid Arteriosclerosis after 4 and 20 Weeks

6 Blum A, Merei M, Karem A, Blum N, Ben Arzi S, Wirsansky I, Khazim K: Effects of tomatoes on the lipid profile. Clin Invest Med 2006;29:298-300.

7 Silaste ML, Alfthan G, Aro A, Kesaniemi YA, Horkko S: Tomato juice decreases LDL cholesterol levels and increases LDL resistance to oxidation. Br J Nutr 2007;98:1251-1258.

8 Sabate J, Oda K, Ros E: Nut consumption and blood lipid levels: a pooled analysis of 25 intervention trials. Arch Intern Med 2010;170:821-827.

-9 Banel DK, Hu FB: Effects of walnut consumption on blood lipids and other cardiovascular risk factors: a metaanalysis and systematic review. Am J Clin Nutr 2009;90:56-63.

10 Frisoli TM, Schmieder RE, Grodzicki T, Messerli FH: Beyond salt: lifestyle modifications and blood pressure. Eur Heart J 2011;32:3081-3087.

$\checkmark 11$ Richard C, Couture P, Desroches S, Charest A, Lamarche B: Effect of the Mediterranean diet with and without weight loss on cardiovascular risk factors in men with the metabolic syndrome. Nutr Metab Cardiovasc Dis 2011;21:628-635.

-12 Dickinson HO, Mason JM, Nicolson DJ, Campbell F, Beyer FR, Cook JV, Williams B, Ford GA: Lifestyle interventions to reduce raised blood pressure: a systematic review of randomized controlled trials. J Hypertens 2006; 24:215-233.

-13 Pinto A, Di Raimondo D, Tuttolomondo A, Fernandez P, Arnao V, Licata G: Twenty-four hour ambulatory blood pressure monitoring to evaluate effects on blood pressure of physical activity in hypertensive patients. Clin J Sport Med 2006;16:238-243.

14 Whelton SP, Chin A, Xin X, He J: Review: aerobic exercise reduces systolic and diastolic blood pressure in adults. Ann Intern Med 2002;136:493-503.

15 Hillbom M, Saloheimo P, Juvela S: Alcohol consumption, blood pressure, and the risk of stroke. Curr Hypertens Rep 2011;13:208-213.

16 Kloner RA, Rezkalla SH: To drink or not to drink? That is the question. Circulation 2007;116:1306-1317.

-17 Avellone G, Di Garbo V, Campisi D, De Simone R, Raneli G, Scaglione R, Licata G: Effects of moderate Sicilian red wine consumption on inflammatory biomarkers of atherosclerosis. Eur J Clin Nutr 2006;60:41-47.

-18 Coimbra SR, Lage SH, Brandizzi L, Yoshida V, da Luz PL: The action of red wine and purple grape juice on vascular reactivity is independent of plasma lipids in hypercholesterolemic patients. Braz J Med Biol Res 2005; 38:1339-1347.

19 Krenz M, Korthuis RJ: Moderate ethanol ingestion and cardiovascular protection: from epidemiologic associations to cellular mechanisms. J Mol Cell Cardiol 2012;52:93-104.

20 O’Keefe JH, Bybee KA, Lavie CJ: Alcohol and cardiovascular health: the razor-sharp double-edged sword. J Am Coll Cardiol 2007;50:1009-1014.

21 Smoliga JM, Baur JA, Hausenblas HA: Resveratrol and health-a comprehensive review of human clinical trials. Mol Nutr Food Res 2011;55:1129-1141.

-22 Droste DW, Iliescu C, Vaillant M, Gantenbein M, De Bremaeker N, Lieunard C, Velez T, Meyer M, Guth T, Kuemmerle A, Chioti A: Lifestyle counseling in patients with carotid arteriosclerosis from Luxemburg should focus more on the reduction of sugar, sodium and saturated fat consumption. Bull Soc Sci Med Grand Duche Luxemb 2013;1:28-38.

23 Ministère de la Santé: Alimentation Saine et Activité Physique. http://www.sante.public.lu/publications/ rester-bonne-sante/alimentation/plan-national-alimentation-saine-activite-physique/plan-nationalalimentation-saine-activite-physique.pdf, Luxembourg, 2007.

24 Mente A, de Koning L, Shannon HS, Anand SS: A systematic review of the evidence supporting a causal link between dietary factors and coronary heart disease. Arch Intern Med 2009;169:659-669.

-25 Damasceno NR, Perez-Heras A, Serra M, Cofan M, Sala-Vila A, Salas-Salvado J, Ros E: Crossover study of diets enriched with virgin olive oil, walnuts or almonds. Effects on lipids and other cardiovascular risk markers. Nutr Metab Cardiovasc Dis 2011;21(suppl 1):S14-S20.

-26 Mursu J, Voutilainen S, Nurmi T, Rissanen TH, Virtanen JK, Kaikkonen J, Nyyssonen K, Salonen JT: Dark chocolate consumption increases HDL cholesterol concentration and chocolate fatty acids may inhibit lipid peroxidation in healthy humans. Free Radic Biol Med 2004;37:1351-1359.

27 Elkind MS, Sciacca R, Boden-Albala B, Rundek T, Paik MC, Sacco RL: Moderate alcohol consumption reduces risk of ischemic stroke: the Northern Manhattan Study. Stroke 2006;37:13-19.

28 Wilkins K: Moderate alcohol consumption and heart disease. Health Rep 2002;14:9-24.

-29 O’Brien E, Asmar R, Beilin L, Imai Y, Mallion JM, Mancia G, Mengden T, Myers M, Padfield P, Palatini P, Parati G, Pickering T, Redon J, Staessen J, Stergiou G, Verdecchia P: European Society of Hypertension recommendations for conventional, ambulatory and home blood pressure measurement. J Hypertens 2003;21:821-848.

30 Parati G, Stergiou GS, Asmar R, Bilo G, de LP, Imai Y, Kario K, Lurbe E, Manolis A, Mengden T, O’Brien E, Ohkubo T, Padfield P, Palatini P, Pickering TG, Redon J, Revera M, Ruilope LM, Shennan A, Staessen JA, Tisler A, Waeber B, Zanchetti A, Mancia G: European Society of Hypertension practice guidelines for home blood pressure monitoring. J Hum Hypertens 2010;24:779-785.

-31 Stevens VJ, Obarzanek E, Cook NR, Lee IM, Appel LJ, Smith WD, Milas NC, Mattfeldt-Beman M, Belden L, Bragg C, Millstone M, Raczynski J, Brewer A, Singh B, Cohen J: Long-term weight loss and changes in blood pressure: results of the Trials of Hypertension Prevention, phase II. Ann Intern Med 2001;134:1-11. 
-32 Adamsson V, Reumark A, Fredriksson IB, Hammarstrom E, Vessby B, Johansson G, Riserus U: Effects of a healthy Nordic diet on cardiovascular risk factors in hypercholesterolaemic subjects: a randomized controlled trial (NORDIET). J Intern Med 2011;269:150-159.

-33 Appel LJ, Moore TJ, Obarzanek E, Vollmer WM, Svetkey LP, Sacks FM, Bray GA, Vogt TM, Cutler JA, Windhauser MM, Lin PH, Karanja N: A clinical trial of the effects of dietary patterns on blood pressure. DASH Collaborative Research Group. N Engl J Med 1997;336:1117-1124.

34 Stewart KJ, Bacher AC, Turner KL, Fleg JL, Hees PS, Shapiro EP, Tayback M, Ouyang P: Effect of exercise on blood pressure in older persons: a randomized controlled trial. Arch Intern Med 2005;165:756-762.

-35 Abe H, Kawano Y, Kojima S, Ashida T, Kuramochi M, Matsuoka H, Omae T: Biphasic effects of repeated alcohol intake on 24-hour blood pressure in hypertensive patients. Circulation 1994;89:2626-2633.

36 Rosito GA, Fuchs FD, Duncan BB: Dose-dependent biphasic effect of ethanol on 24-h blood pressure in normotensive subjects. Am J Hypertens 1999;12:236-240.

-37 Bau PF, Bau CH, Naujorks AA, Rosito GA: Early and late effects of alcohol ingestion on blood pressure and endothelial function. Alcohol 2005;37:53-58.

38 Aguilera MT, de la Sierra A, Coca A, Estruch R, Fernandez-Sola J, Urbano-Marquez A: Effect of alcohol abstinence on blood pressure: assessment by 24-hour ambulatory blood pressure monitoring. Hypertension 1999; 33:653-657.

39 Zilkens RR, Burke V, Hodgson JM, Barden A, Beilin LJ, Puddey IB: Red wine and beer elevate blood pressure in normotensive men. Hypertension 2005;45:874-879.

40 Tatami S, Sarashina A, Yamamura N, Igarashi T, Tanigawara Y: Population pharmacokinetics of an angiotensin II receptor antagonist, telmisartan, in healthy volunteers and hypertensive patients. Drug Metab Pharmacokinet 2003;18:203-211. 